\title{
Comercialização e utilização de agrotóxicos no município de Crisópolis-BA
}

\author{
Commercialization and use of pesticides in the city of Crisópolis-BA \\ Comercialización y uso de plaguicidas en la ciudad de Crisópolis-BA
}

\section{Resumo}

A expansão da produção agrícola e pecuária no Brasil levou a intensificação da utilização de produtos agrotóxicos, fato preocupante diante dos efeitos negativos desses produtos sobre o meio ambiente e saúde humana. A Bahia é um dos principais estados consumidores de agrotóxicos e trabalhos prévios no município baiano de Crisópolis-BA demonstraram ampla utilização desses produtos por sua população. Considerando o potencial lesivo dos agrotóxicos, fica evidente a importância de investigações referentes à sua comercialização para identificação de eventuais problemas e planejamento de ações corretivas. Nesse âmbito, a presente pesquisa teve o objetivo de investigar variáveis relacionadas à comercialização de agrotóxicos no município de Crisópolis-BA no ano de 2021. Dessa forma, informações foram levantadas junto aos estabelecimentos de comercialização de agrotóxicos do município por meio de observações e aplicação de questionários aos proprietários e funcionários dos estabelecimentos. Os dados foram analisados utilizando estatística descritiva e inferencial. Os resultados demonstraram maior tendência de vendas para os produtos com o princípio ativo 2,4-D + picloram. Esses dados sugerem grande demanda e manipulação desses produtos pela população, o que é motivo de preocupação considerando seu potencial toxicológico (classes toxicológicas I). Além disso, verificou-se a preponderante falta de conhecimento por parte dos vendedores acerca do uso seguro dos agrotóxicos. Dado preocupante posto que a ausência da informação sobre o seu manejo correto implica um maior risco de exposição, podendo contribuir para intoxicação do trabalhador rural por esses produtos.

Palavras-chave: Agrotóxico; Comercialização; Toxicologia.

\begin{abstract}
The expansion of agricultural and livestock production in Brazil has led to the intensification of the use of pesticides, a worrying fact given the negative effects of these products on the environment and human health. Bahia is one of the main states that consumes pesticides and previous studies in the Bahia municipality of Crisópolis-BA have shown a wide use of these products by the population. Considering the harmful potential of pesticides, it is evident the importance of investigations regarding their commercialization for the identification of possible problems and planning of corrective actions.. In this context, the present research aimed to investigate variables related to the commercialization of pesticides in the municipality of Crisópolis-BA in the year 2021. Thus, information was collected from the establishments that sell pesticides in the municipality through observations and application of questionnaires to the owners and employees of the establishments. The data were analyzed using descriptive and inferential statistics. The results Showed a greater trend in sales for products with the active ingredient 2,4-D + picloram. These data a great demand and handling of these products by the population, which is a cause for concern considering their toxicological potential (toxicological class I). In addition, there was a preponderant lack of knowledge on the part of sellers about the safe use of pesticides. This is a worrisome fact, since the absence of information about its correct handling implies a greater risk of exposure, which may contribute to the intoxication of rural workers by these products.
\end{abstract}

Keywords: Pesticides; Commercialization; Toxicology. 


\begin{abstract}
Resumen
La expansión de la producción agrícola y ganadera en Brasil ha llevado a la intensificación del uso de pesticidas, hecho preocupante dados los efectos negativos de estos productos sobre el medio ambiente y la salud humana. Bahía es uno de los principales estados consumidores de pesticidas y estudios previos en el municipio baiano de CrisópolisBA mostraron un amplio uso de estos productos por parte de su población. Considerando el potencial nocivo de los plaguicidas, es evidente la importancia de las investigaciones sobre su comercialización para identificar posibles problemas y planificar acciones correctivas. En ese contexto, la presente investigación tuvo como objetivo investigar variables relacionadas con la comercialización de plaguicidas en el municipio de Crisópolis-BA en el año 2021. Así, se recopiló información de los establecimientos de comercialización de plaguicidas del municipio a través de observaciones y aplicación de cuestionarios a los propietarios y empleados de los establecimientos. Los datos se analizaron mediante estadística descriptiva e inferencial. Los resultados mostraron una mayor tendencia de venta de productos con el ingrediente activo 2,4-D + picloram. Estos datos sugieren una gran demanda y manipulación de estos productos por parte de la población, lo que es motivo de preocupación considerando su potencial toxicológico (clases toxicológicas I). Además, hubo un desconocimiento preponderante por parte de los vendedores sobre el uso seguro de plaguicidas. Esto es preocupante ya que la ausencia de información sobre su correcto manejo implica un mayor riesgo de exposición, lo que puede contribuir a la intoxicación de los trabajadores rurales por estos productos.
\end{abstract}

Palabras clave: Plaguicidas; Comercialización; Toxicología.

\title{
1. Introdução
}

A utilização dos produtos agrotóxicos tem crescido de forma exorbitante no mundo e está sujeita a políticas de regulação definidas a partir de evidências científicas das áreas de agronomia, toxicologia humana e ambiental. Tais regulamentações ainda são controversas, uma vez que tendem a sofrer interferências de grupos com distintas finalidades políticas (De Morais, 2019).

A priori, as restrições normativas a esses produtos são elementares para minimizar danos à saúde e ao meio ambiente, assim como atender a demandas de um mercado consumidor que busca por uma alimentação segura em termos de emprego de substâncias agrícolas. Por outro lado, nota-se que a introdução de restrições resulta em menor produtividade agrícola, custos extras para produtores agrícolas e de agrotóxicos, além do uso mais extensivo da terra (De Morais, 2019).

Devido essas nuances, a política de regulação dessas substâncias varia de acordo com a legislação de cada país, ainda que os efeitos nocivos sejam os mesmos (De Morais, 2019). Neste sentido, observa-se que a legislação brasileira sobre agrotóxicos permite que estes produtos sejam comercializados livremente em todo território nacional, enquanto em outras regiões do planeta, a exemplo da União Europeia e nos Estados Unidos, são impostas restrições e/ou banimentos para muitos dos produtos liberados aqui.

Para ilustrar essa variação de normativas entre países, dos dez ingredientes ativos mais utilizados no Brasil, três já foram proibidos na União Europeia (acefato, atrazina e paraquat) (Anvisa, 2017). Além disso, há variações nos limites máximos de resíduos permitidos em alimentos, como por exemplo o limite do ingrediente ativo mais utilizado no Brasil glifosato- para a cultura do milho seria inferior ao que foi imposto nos Estados Unidos, entretanto coincidente ao da União Europeia. Distintivamente, o limite de 2,4-D, o segundo composto mais utilizado no país, é quatro vezes superior ao permitido na União Europeia e outros países (Anvisa, 2018; Pan Consolidated, 2018; Li \& Jennings, 2017).

Há, em verdade, um descontrole sanitário na comercialização de agrotóxicos no Brasil que advém, principalmente, da não efetivação do sistema de vigilância. A flexibilização do acesso a esses produtos se intensifica na medida que políticas de financiamento rural coadjuvante as campanhas publicitárias apoiam incessantemente as indústrias químicas na produção de mais produtos agrotóxicos em detrimento à saúde dos agentes que lidam diretamente com tais substâncias, o trabalhador rural, e, posteriormente, da população geral (augusto et al., 2001).

É válido ressaltar que os canais pelos quais os trabalhadores rurais adquirem os agrotóxicos merecem atenção e investigação, haja vista que diversos aspectos devem ser observados no momento da aquisição dos produtos, que em última análise podem influenciar na maior possibilidade de exposição direta e indireta de todos os agrotóxicos. Neste sentido, a Bahia 
é um dos principais estados consumidores de agrotóxicos, além disso, trabalhos prévios no município baiano de Crisópolis-BA demonstraram ampla utilização desses produtos por sua população (Souza et al., 2015; Souza et al., 2020). Segundo Souza et al. (2020), em pesquisa realizada no município de Crisópolis em 2015, a aquisição desses produtos ocorre com certa frequência de forma ilegal e os estabelecimentos locais não dispõem do receituário agronômico requerido durante a venda dos produtos agrotóxicos.

Considerando o potencial lesivo dos agrotóxicos, fica evidente a importância de investigações referentes à sua comercialização para identificação de eventuais problemas e planejamento de ações corretivas. Nesse âmbito, a presente pesquisa teve o objetivo de investigar variáveis relacionadas à comercialização de agrotóxicos no município de Crisópolis-BA no ano de 2021.

\section{Metodologia}

\section{Tipo de pesquisa}

Trata-se de um estudo de metodologia transversal, realizado no período de março a novembro de 2021, mediante levantamento de dados realizado junto a Agência Estadual de Defesa Agropecuária da Bahia (ADAB) visando a identificação e análise de empresas de venda de produtos agrotóxicos no município de Crisópolis-BA.

\section{Área de estudo}

Crisópolis-BA está localizada no estado da Bahia (figura 1), possui área de unidade territorial de 607,657 km², acompanhada de uma população constituída por 21.835 habitantes, dos quais $60 \%$ destes sãos residentes na zona rural da cidade (IBGE, 2017).

A cidade apresenta características de desenvolvimento da agricultura familiar, sendo o cultivo de lavouras de mandioca, feijão, milho, amendoim e batata doce a principal fonte de renda. Na agricultura, as propriedades podem ser divididas em pequenas e médias com a produção de alimentos, tendo como escopo a subsistência da família, ao passo que determinada parte da produção é comercializada com as indústrias, mercados e feiras da região. As grandes propriedades, em regra, são representadas por fazendas destinadas à pecuária, com criação de bovinos, caprinos e suínos.

\section{Coleta de dados}

Foi empreendido, em consonância com a Agência Estadual de Defesa Agropecuária da Bahia (ADAB) da cidade de Crisópolis-Ba, um levantamento de dados sobre os estabelecimentos de comercialização de agrotóxicos no município, o que veio a permitir a identificação de dois pontos de venda atuantes no mercado no ano de 2021.

A coleta de dados dos estabelecimentos comerciais ocorreu mediante aplicação de questionários semiestruturados aos comerciantes responsáveis pelos estabelecimentos. Possuindo um total de 19 questões, o questionário apresenta 4 seções: 1 identificação comercial; 2- Assistência técnica; 3- Classes agrotóxicas mais comercializadas; 4- Parâmetros de adequação do espaço específico para armazenamento dos agrotóxicos.

\section{Análise de Dados}

Os dados coletados foram tabulados em Microsoft® Office Excel versão 2019 e exportados para o módulo estatístico PSSP (versão 2019) para tratamento dos dados, permitindo a análise dos resultados acerca das variáveis investigadas. 


\section{Aspectos éticos e legais}

O presente estudo foi devidamente submetido à análise do Comitê de Ética em Pesquisa (CEP) da Universidade do Estado da Bahia, respeitando o dispositivo estabelecido na Resolução no 466, de 12 de dezembro de 2012. Suplementarmente, foi aprovado sob o Certificado de Apresentação de Apreciação Ética (CAAE) n 16888019.8.0000.0057. Vale ressaltar que os participantes da pesquisa assinaram o Termo de Consentimento Livre e Esclarecido (TCLE).

\section{Resultados e Discussão}

Apenas 02 (dois) estabelecimentos comerciais que trabalham com a venda de produtos agrícolas que incluem agrotóxicos constam nos registros da Agência Estadual de Defesa Agropecuária da Bahia (ADAB) desse município. Ambas as empresas, aqui denominadas "A" e "B", atuam respectivamente há 5 (cinco) e 20 (vinte) anos na comercialização de produtos agrotóxicos e estão devidamente licenciadas pelos órgãos competentes (Tabela 1).

Tabela 1 - Tempo (anos) e legalidade para comercialização de agrotóxicos, Crisópolis-Ba, Brasil, 2020-2021 (N=2).

\begin{tabular}{ccc}
\hline Empresa & Tempo de comercialização (anos) & Legalidade para comercialização \\
\hline A & 05 & Apto \\
B & $20^{*}$ & Apto \\
\hline
\end{tabular}

*Ressalva: somente há 05 anos emite receituário agronômico. Fonte: Autoria própria (2021).

Segundo o Decreto $\mathrm{n}^{\circ}$ 4.074, de 4 de janeiro de 2002 (BRASIL, 2002), a comercialização de produtos agrotóxicos somente poderá ser realizada mediante registro da empresa nos órgãos fiscalizadores vigentes. Em âmbito estadual, a ADAB, vinculada à Secretaria Estadual da Agricultura, Pecuária, Irrigação, Reforma Agrária, Pesca e Aquicultura (SEAGRI), tem a atribuição de fiscalizar as casas comerciais, as formas de aplicação, bem como o armazenamento e o transporte interno dos agrotóxicos no estado da Bahia (Brasil, 1993; Brasil, 1996). Dessarte, em termo de legalização, as empresas entrevistadas desse município encontram-se dentro dos termos legais e apresentam registro junto a ADAB.

\section{Principais agrotóxicos comercializados}

A respeito dos agrotóxicos de maior volume de vendas identificados, constatou-se 10 produtos citados pelas empresas. A Tabela 2 apresenta esses produtos, identificando seu princípio ativo, nomes comerciais, finalidade de uso, grupo químico, além de classificação toxicológica.

Segundo os entrevistados dos estabelecimentos, há maior venda de produtos do princípio ativo Sulfluramida, comercializado na marca Mirex-s, seguido dos produtos que contêm 2,4-D + picloram ligados ao grupo químico do Ácido ariloxialcanóico + ácido piridinocarboxílico (Tordon, Tucson, Famoso). 
Tabela 2 - Principais agrotóxicos comercializados em Crisopólis-Ba no ano de 2021 pelos estabelecimentos comerciais pesquisados $(\mathrm{N}=2)$, ordenados por volume de vendas.

\begin{tabular}{|c|c|c|c|c|}
\hline $\begin{array}{l}\text { Ingredientes } \\
\text { ativos }\end{array}$ & Nomes comerciais comuns & Finalidade & Grupo Químico & Classificação toxicológica \\
\hline Sulfluramida & Mirex-S & $\begin{array}{l}\text { Inseticida, } \\
\text { bacteriostático }\end{array}$ & $\begin{array}{l}\text { Sulfonamidas } \\
\text { fluoroalifáticas }\end{array}$ & Classe IV \\
\hline 2,4-D + picloram & Tordon, Tucson, Famoso & Herbicida & $\begin{array}{l}\text { Ácido } \\
\text { ariloxialcanóico } \\
\text { ácido } \\
\text { piridinocarboxílico }\end{array}$ & $\begin{array}{r}\text { Classe I } \\
+\quad\end{array}$ \\
\hline $\begin{array}{l}\text { Diclorvós+ } \\
\text { clorpirifós }\end{array}$ & $\begin{array}{l}\text { Brinco mosquicida } \\
\text { para gados }\end{array}$ & $\begin{array}{ll}\text { Inseticida } & \mathrm{e} \\
\text { acaricida } & \end{array}$ & Organofosforado & Classe II \\
\hline Cipermetrina & Barrage & Inseticida & Piretroide & Classe II \\
\hline Triazina & Atrazine & Herbicida & Triazina & Classe III \\
\hline Deltametrina & Butox & Inseticida & Piretroide & Classe IV \\
\hline Glifosato & Roundup & Herbicida & Glicina substituída & Classe IV \\
\hline $\begin{array}{l}\text { Diclorvós } \\
\text { cipermetrina }\end{array}$ & Alatox & Inseticida & $\begin{array}{l}\text { Organofosforado+ } \\
\text { piretroide }\end{array}$ & Classe II \\
\hline
\end{tabular}

Fonte: Autoria própria (2021).

Dentre os agrotóxicos mencionados na tabela 2, o 2,4-D, o Glifosato e a Atrazina estão também entre os 10 mais comercializados no Brasil em 2018, conforme dados divulgados pelo Instituto Brasileiro do Meio Ambiente e dos Recursos Naturais Renováveis (Ibama, 2019). Contudo, em Crisópolis, os agrotóxicos com os princípios ativos 2,4-D e picloram associados na formulação (Ex: Tordon) possuem volumes de comercialização maiores em relação ao glifosato, que no cenário nacional assume a primeira colocação em vendas. Este fato é alarmante uma vez que a associação 2,4-D/picloram apresenta maior toxicidade com relação ao glifosato. Não por acaso, a venda de tais classes é controlada com limite de quantidade para aquisição.

Entre os demais produtos citados pelos comerciantes de agrotóxicos, se observou que $40 \%$ são da classe tóxica IV (pouco tóxicos) e $25 \%$ classe I, extremamente tóxicos (Gráfico 1).

Gráfico 1 - Percentual de agrotóxicos de acordo a classificação toxicológica comercializados no comércio de Crisopólis-Ba, Brasil, 2021(N=2).

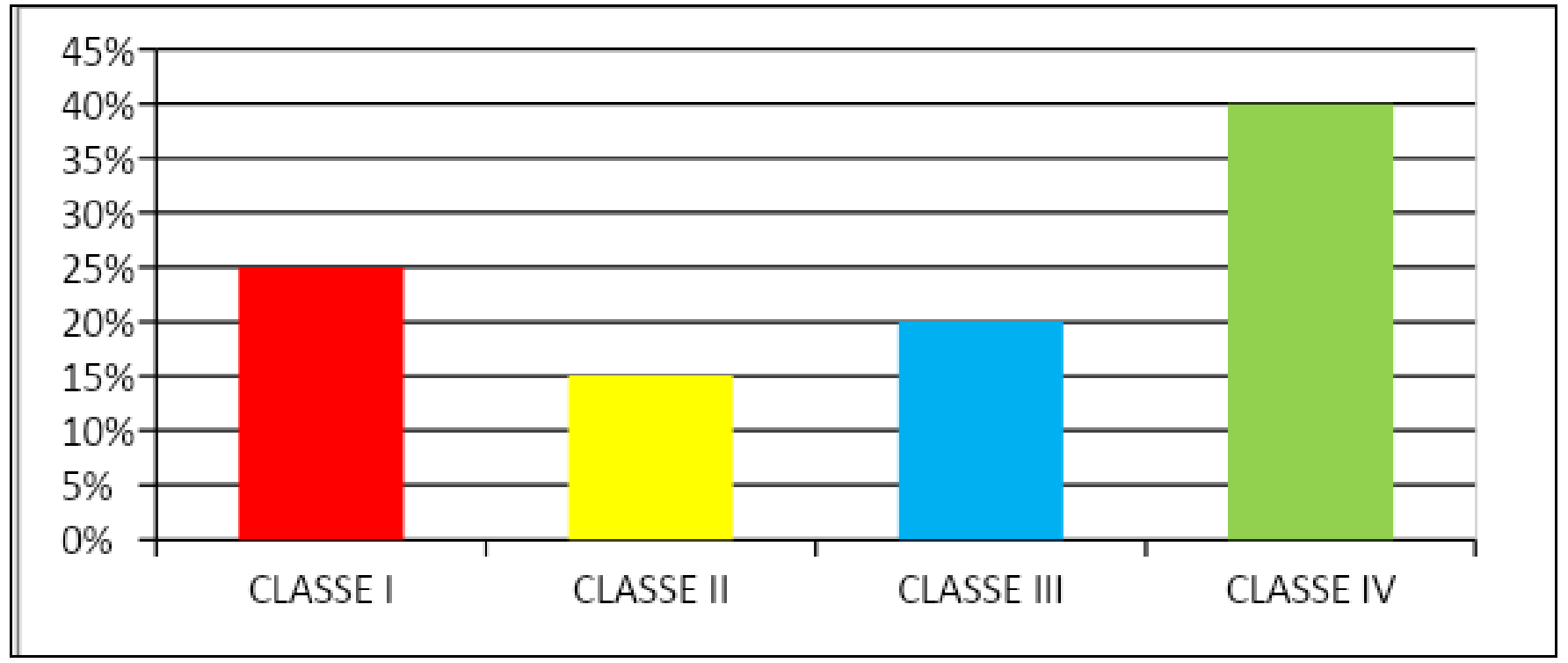

Fonte: Autoria própria (2021). 
Pesquisa semelhante, realizada por De Souza, Faria e Pereira (2017), nesse mesmo município, apura que maior parte dos trabalhadores rurais utilizava o formicida dipil (45,5\%-classe IV- princípio ativo: sulfluramida) seguido do herbicida tordon (25,0\% - classe I- -princípios ativos: 2,4-D + picloram).

Pesquisa realizada por Bedora et al. (2007), na região submédia do Vale do São Francisco, difere dos nossos achados, uma vez que identificaram que $38 \%$ dos produtos comercializados seriam medianamente tóxicos (classe III) e $25 \%$ altamente tóxicos (classe II). Segundo Garcia, Bussacos e Fischer (2005), no Brasil, essa classificação é meramente ilustrativa, uma vez que não há distinção no controle do comércio de produtos classe I (extremamente tóxicos) ou da classe IV (pouco tóxicos). Cabe destacar que a dosagem de $5 \mathrm{mg} / \mathrm{kg}$ definida para produtos classe I tem capacidade de levar a óbito uma pessoa adulta (Brasil, 1997).

\section{Emissão de receituário agrônomo e recolhimento das embalagens}

A tabela 03 demonstra que as vendas de agrotóxicos realizadas pelas empresas entrevistadas ocorrem mediante a prescrição do profissional habilitado para a atividade (Agrônomo). Cabe ressaltar que, segundo artigo $13^{\circ}$ da Lei 7.802 , a venda de agrotóxicos e afins deve ser feita mediante receituário agronômico, prescrito por profissional legalmente habilitado (Brasil, 1989).

Pesquisa realizada por Silva et al. (2018), em estabelecimentos comerciais na cidade de Sousa-PB, tem resultados que se assemelham aos da nossa pesquisa, uma vez que todas as empresas desta cidade trabalhavam com vendas sob receituário agrônomo. Em contrapartida, os nossos achados são divergentes da pesquisa realizada em 2015 na própria cidade de Crisópolis, a qual mostra que nenhum dos três comércios locais possuía agrônomo e, tampouco, emitia receituário agronômico (De Souza; Farias; Pereira et al., 2017). Dessarte, nota-se que os dados atuais mostram um avanço positivo nessa questão no comércio crisopolense de agrotóxicos.

Contudo, observa-se, mediante as entrevistas com os trabalhadores rurais realizadas por De Souza, Faria e Pereira (2017), que nenhum desses participantes utilizava os receituários agrônomos como parâmetro de dosagem. Esses dados destacam uma drástica e positiva mudança entre os dados de 2015 e 2021. Espera-se que, de fato, todos os agricultores do município que utilizem esses produtos assim o façam via receituário. Embora animadores, os dados não eliminam a necessidade de fiscalização de órgãos como ADAB em futuras pesquisas.

Outro aspecto importante investigado foi referente ao recolhimento das embalagens dos agrotóxicos por parte das empresas entrevistadas. Sabe-se que essa prática é de grande importância para evitar danos à saúde humana e ao ambiental.

$\mathrm{Na}$ presente pesquisa, apesar das empresas entrevistadas alegarem que realizam o recolhimento ou recebimento das embalagens de agrotóxicos vazias, foi constatado que raramente isso é feito pela população crisopolense e, quando eventualmente ocorre, seria dirigida apenas para vasilhames de produtos extremamente tóxicos como o Tordon; Famoso; Tucson; Folidol; Ayts. Ademais, com relação à tríplice lavagem, ambas empresas afirmam que, em regra, os consumidores não realizam (dados omitidos da tabela).

Tabela 3 - Vendas de agrotóxico sob prescrição e recolhimento das embalagens vazias no comércio de Crisopólis-Ba, Brasil, 2021(N=2).

\begin{tabular}{lll}
\multicolumn{1}{c}{ Variáveis } & Empresa A & Empresa B \\
\hline Venda com prescrição de um profissional & Sim & Sim \\
\hline Recolhimento das embalagens vazias & Sim & Sim \\
\hline
\end{tabular}

Fonte: Autoria própria (2021). 
Diante desses resultados, percebe-se a necessidade de uma política efetiva de incentivo dessas empresas entrevistadas, bem como dos consumidores dos produtos, quanto a orientação para devolverem as embalagens. Os resultados de Credidio (2019), em pesquisa realizada em 2019 em Crisópolis, descrevem que a minoria dos trabalhadores entrevistados do município retorna as embalagens. Uma hipótese para explicar esses dados, seriam possíveis custos e burocracias por parte dos comerciantes para realizações do preconizado na legislação. Nesse sentido, um ponto interessante citado por Monquero, Inácio e Silva (2009) é que, por muitas vezes, os agricultores deixam de realizar a destinação correta das embalagens devido a burocracias, como a exigência da nota fiscal dos produtos e a devolução das embalagens na cidade em que a compra foi realizada, gerando custos adicionais.

Através de consulta ao website do Instituto Nacional de Processamento de Embalagens Vazias (INPEV), em janeiro de 2021, não foram encontrados postos ou centrais de recebimento de embalagens que fossem próximos a Crisópolis. Isso escancara a necessidade de ampliação da cobertura desses serviços para alcançar municípios menores como o citado nessa pesquisa. Dessarte, nota-se uma real necessidade dos órgãos públicos em facilitar tanto a parte burocrática quanto o acesso aos postos de recebimento das embalagens, visando minimizar a problemática supramencionada.

Outrossim, segundo a Norma Brasileira no 13968 de 1997 (Abnt, 1997), as embalagens rígidas de defensivos agrícolas, para que possam retornar ao posto de recebimento ou algo do gênero, devem passar pela tríplice lavagem ou lavagem sob pressão feita pelo agricultor, ainda no campo. Trata-se de procedimento imprescindível para a descontaminação das embalagens, preparando-as para o processo de reciclagem pelo Programa de Recebimento de Embalagens Vazias de Agrotóxicos. Além disso, essa prática, quando ocorrida durante a preparação da calda, evita possíveis desperdícios do produto agrícola, reduzindo, assim, os riscos de contaminação do meio ambiente. Apesar disso, nota-se que o comportamento habitual da população em estudo vai de encontro ao proposto na legislação brasileira, algo que interromperia o ciclo de vida das embalagens, intensificando ainda mais a possibilidade de exposição a esses produtos e a poluição ambiental.

\section{Orientações técnicas destinadas aos compradores de produtos agrotóxicos}

As orientações técnicas prestadas por casas comerciais de produtos agrotóxicos são, sobretudo, essenciais e primordiais para que haja um manejo adequado desses compostos químicos por parte dos agricultores. Quando questionados quanto ao fornecimento de orientações aos indivíduos que adquirem os agrotóxicos, os comerciantes responderam negativamente. Informações referentes a formas de manuseio, aplicação, armazenamento, transporte e prevenção de acidentes com agrotóxicos, por exemplo, não são repassadas aos trabalhadores rurais (Tabela 4).

A preponderante falta de orientação dos vendedores sobre o uso do agrotóxico reporta um dado preocupante. Como já referido, a manipulação e/ou utilização inadequada desses produtos traz implicações ambientais e à saúde dos aplicadores/manipuladores e demais indivíduos de forma indireta. Outrossim, é importante salientar que, por vezes, os vendedores erram na indicação dos agrotóxicos, o que favorece a utilização incorreta por cultura e por dosagem, contribuindo, dessa forma, para a resistência das pragas (Bedora et al., 2007). 
Tabela 4 - Tipos de orientações técnicas realizadas pelas empresas de venda de agrotóxicos aos trabalhadores rurais, Crisopólis-Ba, Brasil, 2021(N=2).

\begin{tabular}{|c|c|c|}
\hline VARIÁVEIS & EMPRESA A & EMPRESA B \\
\hline Forma de manuseio & Não & Não \\
\hline Forma de aplicação & Não & Não \\
\hline Armazenamento & Não & Não \\
\hline Transporte & Não & Não \\
\hline Tipo de Cultura & Não & Não \\
\hline Prevenção de Acidentes & Não & Não \\
\hline Primeiros socorros & Não & Não \\
\hline Uso de EPI's & Não & Não \\
\hline
\end{tabular}

Fonte: Autoria própria (2021).

Tais dados divergem da pesquisa realizada na cidade de Souza-PB (Silva et al., 2019) que descreve a preocupação dos comerciantes das empresas em prestar uma assistência técnica completa aos seus clientes quanto aos produtos adquiridos.

\section{Parâmetros de adequação do espaço específico para armazenamento dos agrotóxicos}

A preparação do espaço físico do estabelecimento comercial integra as boas práticas de segurança para o trabalho e comercialização de agrotóxicos (Andav, 2017). Nesse sentido, investigou-se, junto aos comerciantes, os parâmetros de adequação do estabelecimento quanto ao armazenamento desses produtos.

Observou-se que as não conformidades das empresas ocorrem devido a ausências de chuveiro de emergência, equipamentos contra incêndio e de rotas de fuga em caso de incêndio ou emergência (Tabela 5). Além do mais, na empresa B, identifica-se que a localização do estabelecimento não seria adequada (região de grande movimentação de público). É importante mencionar que seu proprietário, buscando atender a estas orientações técnicas, encontra-se em processo de construção de outro armazém em localidade segura.

Tabela 5 - Parâmetros de adequação dos estabelecimentos comerciais no espaço específico para armazenamento dos agrotóxicos, Crisópolis-Ba, Brasil, $2020(\mathrm{~N}=2)$.

\begin{tabular}{|c|c|c|}
\hline $\begin{array}{l}\text { Parâmetro analisado de adequação do espaço para armazenamento dos } \\
\text { agrotóxicos }\end{array}$ & Empresa A & Empresa B \\
\hline Paredes de alvenaria, com pintura à base de tinta lavável ou a óleo & Sim & Sim \\
\hline Piso de material impermeável (cimento, cerâmica, lajota, material não poroso) & Sim & Sim \\
\hline Estrados e/ou prateleiras para acondicionamento dos produtos & Sim & Sim \\
\hline Placa de perigo: "Produtos tóxicos" & Sim & Sim \\
\hline Arejamento e iluminação adequados & Sim & Sim \\
\hline $\begin{array}{l}\text { Equipamentos de proteção para os empregados (pelo menos, luvas, respirador, botas e } \\
\text { avental) }\end{array}$ & Sim & Sim \\
\hline $\begin{array}{l}\text { Localização adequada: não estar próximo de habitações, longe do alcance de crianças e } \\
\text { de animais }\end{array}$ & Sim & Não \\
\hline Chuveiro de emergência & Não & Não \\
\hline Equipamentos de proteção contra incêndios & Não & Não \\
\hline Rotas de fuga em caso de incêndio ou emergência & Não & Não \\
\hline Possui alvará de funcionamento da prefeitura & Sim & Sim \\
\hline
\end{tabular}

Fonte: Autoria própria (2021).

Um dos parâmetros de adequação avaliados que se encontra em não conformidade para ambas empresas consiste na 
ausência de certos Equipamentos de Proteção Coletiva (EPCs), como chuveiros e equipamentos de proteção contra incêndios. Esses resultados são preocupantes dada a importância desses equipamentos. EPCs proporcionam a preservação da saúde e integridade dos trabalhadores. Ao usufruir deles, o trabalhador evita ou, na pior das hipóteses, reduz as lesões de forma que venha a impactar, numa menor escala, todos os presentes no ambiente (Andav, 2017). Segundo NBR 16291, o chuveiro de emergência com lava olhos é imprescindível para a descontaminação cutânea, caso aconteça uma exposição desse gênero, algo que deveria existir nos armazéns das empresas pesquisadas.

Adicionalmente, em sua grande maioria, esses produtos são inflamáveis, o que aumenta a importância da presença dos extintores de incêndio numa distância inferior a $5 \mathrm{~m}$ da entrada principal da edificação, os quais servirão para o combate de eventuais incêndios. Para acidentes deste gênero ou outros afins que envolvam produtos tóxicos, deve viabilizar as rotas de fuga, também denominadas de saída de emergência, as quais compreendem acessos ou rotas de saída, rampas ou escadas objetivando a proteção coletiva desses trabalhadores (Andav, 2017).

A ausência de equipamentos de combate a incêndio e rota de fuga representa, além do risco para proteção dos funcionários, um potencial problema para os moradores circunvizinhos, ao passo que um possível incêndio poderia tomar maiores dimensões se caso viesse a acontecer.

Dessa forma, embora pouco numerosos, os parâmetros de adequação identificados em não conformidade em ambas empresas são importantes e impactam negativamente na proteção dos trabalhadores ali presentes, podendo tomar dimensões maiores.

Importante é ressaltar que, os comerciantes de produtos agrotóxicos devem estar cadastrados na ADAB que, dentre as várias atribuições cabíveis a esse órgão, deverá realizar inspeção do armazém que condiciona os compostos químicos. Tal inspeção deve ocorrer, no mínimo, três (03) vezes ao ano, para atestar a viabilidade técnica da empresa, em conformidade com o Manual de Fiscalização de Agrotóxicos e Afins da ADAB. Todavia, as empresas pesquisadas relataram que nunca foram notificadas por tais irregularidades.

Deste modo, as inadequações identificadas nos estabelecimentos são motivos de preocupação, devendo ser urgentemente corrigidas a fim de garantir a proteção coletiva dos seus funcionários e dos moradores circunvizinhos. Ademais, espera-se a fiscalização efetiva do fiscal da ADAB (engenheiro agrônomo) para articular junto as empresas a correção de tais irregularidades.

\section{Considerações Finais}

A presente pesquisa permitiu o levantamento de dados inerentes à comercialização e à utilização de produtos agrotóxicos no município de Crisópolis-Ba. Identificou-se junto aos estabelecimentos comerciais de agrotóxicos do município, maior tendência de vendas para os compostos com o princípio ativo 2,4-D + picloram (classificação I: extremamente tóxicos). Considerando estudos anteriores que apontam dados de exposição insegura a agrotóxicos por trabalhadores do município (por exemplo: baixa adesão a utilização de EPIs), incorpora sugerir que essa população estaria consideravelmente exposta a esses produtos de elevada toxicidade.

Soma-se a isso, a informação aqui levantada junto aos comerciantes do não fornecimento de orientações básicas quanto à utilização segura desses produtos aos consumidores que o adquirem. Dado preocupante, posto que a ausência da informação sobre o seu manejo correto implica em maior risco de exposição e intoxicação desse trabalhador rural.

Ademais, embora pouco numerosos, importantes aspectos estruturais concernentes a adequação dos espaços de depósito dos produtos nos estabelecimentos comerciais apresenta não conformidade, em especial referentes a Equipamentos de Proteção Coletiva. O que carece de correção.

Dessarte, é imprescindível que sobrevenha uma maior fiscalização dos órgãos responsáveis junto aos comerciantes 
deste município, de modo que venha orientá-los a realizar a capacitação profissional dos seus respectivos vendedores, com o propósito de promover uma assistência técnica eficaz aos trabalhadores rurais além das necessárias adequações dos espaços físicos.

\section{Referências}

Anvisa - Agência Nacional De Vigilância Sanitária. (2017). Listas de ingredientes ativos com uso autorizado e banidos no Brasil. Anvisa <https:// bit.ly/2WD8grj>.

Anvisa - Agência Nacional De Vigilância Sanitária. (2018). Regularização de produtos - agrotóxicos: monografias autorizadas. Anvisa, Brasília.

Andav. (2017). Manual De Armazenamento De Defensivos Agrícolas E Medicamentos Veterinários. Associação Nacional dos Distribuidores de Insumos Agrícolas e Veterinários - Campinas-SP.1 ${ }^{a}$ Edição - 2017

Adab. (2021). Manual De Fiscalização De Agrotóxicos A E Afinshttp://www.adab.ba.gov.br/arquivos/File/MANUALDEFISCALIZAcaOTEXTO.pdf. Acessado em: 12 de junho de 2021.

Augusto L. G. S, Gurgel I. G. D, Florêncio L, \& Araujo A. C. P. (2001). Exposição ocupacional aos agrotóxicos e riscos sócio-ambientais: subsídio para ações integradas no estado de Pernambuco. In: Augusto L.G.S., Florencio, L, Carneiro RM, organizadores. Pesquisa (ação) em saúde ambiental - contexto, complexidade, compromisso social. Recife: Universitária. p. 57-69.

Credidio, G. C. (2020). Caracterização da exposição de trabalhadores rurais a agrotóxicos em um município da Bahia. 2020. 109f. Trabalho de Conclusão de Curso (Graduação) - Colegiado de Farmácia, Departamento de Ciências da Vida. Universidade do Estado da Bahia.

De Moraes, R. F. (2019). Agrotóxicos No Brasil: Padrões De Uso, Política Da Regulação E Prevenção Da Captura Regulatória. Texto para discussão / Instituto de Pesquisa Econômica Aplicada- Ipea. Brasília.

Bedora, C. N. G., Ramos, L. O., Rego, M. A. V., Pavão, A. C., \& Augusto, L. G. S. (2007). Avaliação E Reflexos Da Comercialização E Utilização De Agrotóxicos Na Região Do Submédio Do Vale Do São Francisco. Revista Baiana de Saúde Pública 31(1), 68-76.

Brasil. (2002). Decreto $\mathrm{n}^{\mathrm{o}}$ 4.074, de 4 de janeiro de 2002. http://www.planalto.gov.br/ccivil_ 03/decreto/2002/d4074.htm. "Ex. incorreto: "Brasil. Lei estadual de agrotóxico n. ${ }^{\circ} 6.455$ de 25 de janeiro de 1993.

Brasil. (1993). Lei estadual de agrotóxico n. ${ }^{\circ} 6.455$ de 25 de janeiro de 1993.

Brasil. (1989). Lei $n^{o}$ 7.802, de 11 de julho de 1989. Brasília: DF. https://www.camara.leg.br/proposicoesWeb/prop_mostrarintegra,jsessionid=614EC1856F7D8D7AE269B05055528F1B7D.proposicoesWeb Externo1?codteor $=356265 \&$ filename $=$ LegislacaoCitada $+-P L+6189 / 2005$.

Brasil. (1996). Decreto estadual ${ }^{\circ}{ }^{\circ} 6.033$ de 06 de dezembro de 1996.

Brasil. (1997). Ministério da Saúde. Secretaria de Vigilância Sanitária. Manual de vigilância da saúde de populações expostas a agrotóxicos. Brasília: Organização Pan-Americana da Saúde.

De Souza, J. P., Faria, H. A., \& Pereira, R. S. F. (2017). Uso de agrotóxicos pelos trabalhadores rurais do município de Crisópolis-BA. Estação científica (UNIFAP), 7(3), 107-117.

Garcia, E. G., Bussacos, M. A., \& Fischer, F. M. (2005). Impact of legislation on registration of acutely toxic pesticides in Brazil. Rev. Saúde Pública oct,39(5):832-9.

Gil, A. C. (2012). Como elaborar projetos de pesquisa. (6a ed.), Atlas.

Ibge - Instituto Brasileiro De Geografia E Estatística. (2017). Censo Agropecuário 2017. IBGE.

Ibama. (2020). Consumo de agrotóxicos $\quad$ e $\quad$ afins $\quad(2000 \quad$ http://ibama.gov.br/phocadownload/qualidadeambiental/relatorios/2017/Grafico-Consumo_agrotoxicos_2000-2017.

Ibama. (2019). Instituto Brasileiro do Meio Ambiente e dos Recursos Naturais Renováveis. (2019). Consolidação de dados fornecidos pelas empresas registrantes de produtos técnicos, agrotóxicos e afins, conforme art. 41 do Decreto $n^{\circ} 4.074 / 2002$. Brasília, DF. 
Research, Society and Development, v. 11, n. 3, e4011326206, 2022

(CC BY 4.0) | ISSN 2525-3409 | DOI: http://dx.doi.org/10.33448/rsd-v11i3.26206

Monquero, P. A., Inácio, E. M. \& Silva, A. C. (2009). Levantamento de agrotóxicos e utilização de equipamento de proteção individual entre os agricultores da região de Araras. Arq. Inst. Biol. 76(1), 135-9.

Li, Z., Jennings, A. (2017). Worldwide regulations of standard values of pesticides for human health risk control: a review. International Journal of Environmental Research and Public Health, 14(7), 826, 22.

Pan Consolidated. (2018). list of banned pesticides. Pesticide Action Network International, https://bit.ly/2g5P1Tu.

Souza, J. P., Pereira, A. P. G. S., Pereira, R. S. F., Faria, H. A., Souza, E N., Santos, T. J., \& Miranda, C. (2020). Classes de agrotóxicos mais utilizadas pelos trabalhadores rurais no município de Crisópolis/BA. Scire Salutis, 10(3), 82-87. http://doi.org/10.6008/CBPC22369600.2020.003.0010.

Silva, L. L. H., Pinto, É. N. F., Lucena, S. C. B., Bezerra, J. C., \& Silva, Y. D. L. (2019). Agrotóxicos e seus riscos em estabelecimentos comerciais na cidade de Sousa-PB. Divulgação científica e tecnológica do IFB/ $n^{\circ} 44$. Revista Pincipia. 